\title{
The anti-apoptotic effect of fucoxanthin on carbon tetrachloride-induced hepatotoxicity
}

\author{
Mieko Kaneko1, Takeaki Nagamine ${ }^{2}$, Kyoumi Nakazato² and Masatomo Mori ${ }^{1}$ \\ 'Department of Medicine and Molecular Science, Gunma University Graduate School of Medicine, \\ 3-39-22 Showa-machi, Maebashi, Gunma 371-8514, Japan \\ ${ }^{2}$ Graduate School of Health Sciences, Gunma University, 3-39-22 Showa-machi, Maebashi, Gunma 371-8514, Japan
}

(Received November 18, 2012; Accepted December 25, 2012)

\begin{abstract}
This study evaluated the anti-apoptotic activity of fucoxanthin in carbon tetrachloride $\left(\mathrm{CCl}_{4}\right)$-induced hepatotoxicity. An in vitro study using the 3-(4,5-dimethylthiazol-2-yl) 2,5-diphenyltetrazolium bromide (MTT) assay clearly demonstrated an attenuation of $\mathrm{CCl}_{4}$-induced hepatotoxicity with fucoxanthin. This effect was dose-dependent; $25 \mu \mathrm{M}$ was more effective than $10 \mu \mathrm{M}$ of fucoxanthin for attenuating the hepatotoxicity induced by $5 \mathrm{mM}$ of $\mathrm{CCl}_{4}$. Acute $\mathrm{CCl}_{4}$-hepatotoxicity in rats, with numerous cells positive for the terminal deoxynucleotidyl - transferase (TdT) -mediated deoxyuridine triphosphatedigoxigenin (dUTP) nick-end labeling (TUNEL) stain were seen in the pericentral area of the hepatic lobule. Oral pretreatment of $\mathrm{CCl}_{4}$ - injected rats with fucoxanthin significantly reduced hepatocyte apoptosis. Fucoxanthin was immunohistochemically shown to increase heme oxygenase-1 expression in the cultured liver cells of $\mathrm{Hc}$ cells and TRL1215 cells. By oral pretreatment of $\mathrm{CCl}_{4}$-injected rats with fucoxanthin, the hepatic heme oxygenase-1 protein levels were significantly increased compared to those not pretreated with fucoxanthin. Heme oxygenase-1 mRNA expression after $\mathrm{CCl}_{4}$ injection was higher in the $\mathrm{CCl}_{4}+$ fucoxanthin group than in the $\mathrm{CCl}_{4}$ group, although the difference was not significant. The findings suggest that fucoxanthin attenuates hepatocyte apoptosis through heme oxygenase-1 induction in $\mathrm{CCl}_{4^{-}}$ induced acute liver injury.
\end{abstract}

Key words: Fucoxanthin, Apoptosis, Heme oxygenase-1, Carbon tetrachloride, Hepatotoxicity

\section{INTRODUCTION}

Fucoxanthin is a marine carotenoid found in wakame (undaria pinnatifida) and Hijiki (Hijikia fusiformis) and has certain remarkable biological properties, including antioxidant activity (Miyashita, 2009; Kim et al., 2010), an anti-inflammatory effect (Sakai et al., 2009), an anti-carcinogenic effect (Hosokawa et al., 2004; Kotake-Nara et al., 2005; Yu et al., 2011) and even utility as an anti-obesity agent (Maeda et al., 2005; Abidov et al., 2010). The major structural difference between fucoxanthin and the other carotenoids is the presence of an unusual allenic bond, and this bond was shown to be responsible for the higher antioxidant activity of fucoxanthin (Dembitsky and Maoka, 2007; Sachindra et al., 2007). The difference, however is that fucoxanthin acts as an antioxidant under hypoxic conditions, whereas other carotenoids have practically no quenching abilities. Under hypoxic conditions, fucoxanthin equimolar- ly reacted with 1,1-diphenyl-2-picrylhydrazyl (DPPH) as a radical quencher, whereas other carotenoids scarcely reacted with DPPH (Nomura et al., 1997). As most tissues under physiological conditions have a low oxygen presence, fucoxanthin is suggested to have clinical potential as a therapeutic carotenoid for reactive oxygen species (ROS)-associated disorders (D'Orazio et al., 2012; Abidov et al., 2010). It is worth mentioning that fucoxanthin also contains an $\alpha, \beta$ - unsaturated carbonyl group, and may function as a Michael acceptor which can react with important proteins such as Keap 1 in the nuclear factor E2-related factor-2 ( $\mathrm{Nrf2}$ ) system. A recent in vitro study showed that fucoxanthin enhanced heme oxygenase-1 (HO-1) and NAD(P)H dehydrogenase quinone 1 expression in murine hepatic BNL CL.2 cells through the activation of the $\mathrm{Nrf} 2$ / antioxidant response element (ARE) (Liu et al., 2011).

Carbon tetrachloride $\left(\mathrm{CCl}_{4}\right)$ is a well-known chemical that is used for the induction of acute and chronic liver

Correspondence: Takeaki Nagamine (E-mail: mine@health.gunma-u.ac.jp) 
injury characterized by pericentral and midzonal necrosis (Slater, 1966). The trichloromethyl radical generated during the metabolism of $\mathrm{CCl}_{4}$ interacts with oxygen to form the trichloromethyl peroxy radical, a highly reactive species. Trichloromethyl and its peroxy radical are capable of binding to proteins and lipids, or of abstracting a hydrogen atom from an unsaturated lipid, initiating lipid peroxidation and liver damage (Wong et al., 1995; Manibusan et al., 2007). It is well known that oxygen partial pressure can direct the course of $\mathrm{CCl}_{4}$ hepatotoxicity, and the location of $\mathrm{CCl}_{4}$-induced damage mirrors the oxygen gradient across the hepatic lobule (Ozaki and Masuda, 1993). Cellular responses to toxin involve a number of defensive processes aimed at minimizing cell damage and redressing the balance of homeostasis, and the toxicity is commonly manifested in part as cellular apoptosis (Thomas et al., 2001). Hepatocyte apoptosis is likely to play an important role in the development of $\mathrm{CCl}_{4}$-induced liver injury and sometimes either precedes the onset of necrosis or coexists with it (Herrera et al., 2001; Weber et al., 2003). Therefore, understanding the mechanism of hepatocyte apoptosis is one of the primary goals related to the designing of future therapies for hepatic injury.

The Keap1/ Nrf2/ARE signaling pathway has emerged as an important regulator of the mammalian defense system for the detoxification of agents such as $\mathrm{CCl}_{4}$, acetaminophen and furosemide, enabling adaptation to chemical and oxidative stress (Goldring et al., 2004; Lee and Johnson, 2004; Randle et al., 2008; Wen et al., 2006). Under normal physiological conditions, Nrf2 resides in the cell cytoplasm where it associates with a repressor protein, Keap1 (Itoh et al., 1999). Upon disruption of this interaction, $\mathrm{Nrf} 2$ is released and migrates to the nucleus where it binds to the ARE present in the promoter regions of many stress-activated genes, including HO-1 and the glutamate- cysteine ligase catalytic subunit (Weber et al., 2003). This indicates that the cell is primed to respond to a chemical insult through rapid up-regulation of Nrf2-driven defensive proteins. As was mentioned above, fucoxanthin may participate in the Nrf2/ARE system and act as a radical quencher under hypoxia, so this xanthophyll is considered to have a potentially protective effect against $\mathrm{CCl}_{4}$-induced toxic liver injury. In this study, we investigated the anti-apoptotic effect of fucoxanthin on $\mathrm{CCl}_{4}$ induced hepatotoxicity using in vitro and in vivo models.

\section{MATERIALS AND METHODS}

\section{Reagents}

Chemicals: $\mathrm{CCl}_{4}$ and fucoxanthin were purchased from the Wako Pure Chemical Industries, Ltd. (Osaka,
Japan). Solutions of $\mathrm{CCl}_{4}$ were prepared in olive oil $(1: 3 \mathrm{v} / \mathrm{v})$ before the experiments. Fucoxanthin was dissolved in a solution of $0.5 \%$ sodium carboxymethyl cellose, $0.5 \%$ Tween 80 and ultra pure water to obtain a final concentration of $0.5 \%(\mathrm{w} / \mathrm{v})$. William's medium $\mathrm{E}$ and $10 \%$ fetal bovine serum (FBS) were obtained from Sigma Aldrich (St Louis, MO, USA). RIPA lysis buffer was obtained from Santa Cruz Biotechnology (Santa Cruz, CA, USA) and the other chemicals and solvents were of analytical grade. Antibodies to HO-1 (rabbit polyclonal) and heat shock protein 25 (Hsp25) (rabbit polyclonal) were purchased from Stressgen Bioreagents (Ann Arbor, MI, USA) and Enzo Life Science (Farmingdale, NY, USA), respectively. Anti-rabbit IgG and anti-mouse IgG were from GE Healthcare (Buckinghamshire, UK).

\section{Cell culture and experiments in vitro \\ Cell culture}

TRL1215 cell line was originally derived from the liver of a new-born Fisher 344 rat (Nagamine et al., 2008) and kindly donated by Prof. Waalkes (MP) (National Cancer Institute at NIEHS, USA). Hc cells (ACBRI 3716) were initiated from normal human liver tissues (Osawa et al., 2001). These cells were cultured in William's medium E, supplemented with 10\% FBS, $1 \mathrm{mM}$ glutamine, $100 \mathrm{U} / \mathrm{ml}$ penicillin, and $100 \mu \mathrm{g} / \mathrm{ml}$ streptomycin. Cultures were maintained in a humidified atmosphere of $5 \% \mathrm{CO}_{2}$ at $37^{\circ} \mathrm{C}$.

\section{Cellular viability assay (MTT Assay) in TRL1215 cells}

TRL1215 cells were plated at $1 \times 10^{3}$ cells cells per well in five 96-well tissue culture plates and grown in $10 \% \mathrm{FBS}$ fortified media for $48 \mathrm{hr}$ prior to treatment. Fucoxanthin was added directly to the culture medium of each plate to give a final concentration of $0,0.5,1,10$ or $25 \mu \mathrm{M}$. After $12 \mathrm{hr}$ incubation, cells were exposed to various concentrations of $\mathrm{CCl}_{4} ; 0,0.1,0.5,1.0,2.0$ or 5 $\mathrm{mM}$. The relative number of viable cells in each well was determined $20 \mathrm{hr}$ after the administration of $\mathrm{CCl}_{4}$ using a 3-(4,5-dimethylthiazol-2-yl) 2,5-diphenyltetrazolium bromide (MTT) assay according to the manufacturer's instructions (Roche Diagnostics, Mannheim, Germany). Briefly, $5 \mu$ l of MTT reagent was added to each well. After $4 \mathrm{hr}$ incubation at $37^{\circ} \mathrm{C}$, the media were removed and intracellular formazan products were lysed by the addition of $100 \mu$ of dimethyl sulfoxide. The absorbance was recorded at $550 \mathrm{~nm}$ using a plate reader (MPRA4, Toso, Tokyo, Japan).

Immunohistochemistry of HO-1 in cultured liver cells TRL1215 cells and Hc cells were plated at $1 \times 10^{4}$ cells 
Anti-apoptotic effect of fucoxanthin on $\mathrm{CCl}_{4}$ toxicity

per well in 4-well chamber slides and grown in 10\% FBS fortified media for $48 \mathrm{hr}$ prior to treatment. Cells were exposed to 0 or $5 \mu \mathrm{M}$ of fucoxanthin for $24 \mathrm{hr}$, and then HO-1 was stained immunohistochemically as follows. The plates were treated with methanol containing $0.3 \% \mathrm{H}_{2} \mathrm{O}_{2}$ for $30 \mathrm{~min}$ to eliminate endogenous peroxidase activity. The plates were immersed in hot $0.01 \mathrm{~mol} / \mathrm{l}$ citrate buffer ( $\mathrm{pH}$ 6.0) and heated in a microwave for antigen retrieval. Then the plates were incubated with antibodies against HO-1 for $120 \mathrm{~min}$ at room temperature. After washing 3 times using PBS with $0.01 \%$ Tween 20 (PBS-T), the plates were incubated in a color reaction solution $(150 \mathrm{ml}$ of $0.05 \mathrm{~mol} /$ Tris- $\mathrm{HCl}$ buffer, $30 \mathrm{mg}$ diaminobenzidine, $10 \mu \mathrm{l}$ of $\mathrm{H}_{2} \mathrm{O}_{2}$ ) for $30 \mathrm{~min}$ at room temperature. Finally, the plates were counter-stained with Mayer's hematoxylin.

\section{Animals and treatment procedures}

Male Wistar rats ( 8 weeks of age) were purchased from CLEA Japan. Inc. (Tokyo, Japan). They were housed in the animal facility of Gunma University at a constant temperature and under a 12/12-hr light/dark cycle, and maintained on a standard CE-2 diet purchased from CLEA Japan. Inc. (Tokyo, Japan). The rats were acclimated for 1 week prior to use. All animal procedures were carried out in accordance with the guidelines for experiments using experimental animals at Gunma University.

After an over night fast, rats were randomly assigned to four experimental groups; control (olive oil) group $(\mathrm{n}=3)$, fucoxanthin group $(\mathrm{n}=3), \mathrm{CCl}_{4}$ group $(\mathrm{n}=5)$ and $\mathrm{CCl}_{4}+$ fucoxanthin group $(\mathrm{n}=5)$. The fucoxanthin and $\mathrm{CCl}_{4}+$ fucoxanthin groups were administered $50 \mathrm{mg} / \mathrm{kg}$ (B.W) of fucoxanthin by direct stomach intubation. Four hour later, the $\mathrm{CCl}_{4}$ group and $\mathrm{CCl}_{4}+$ fucoxanthin group were injected intraperitoneally with $0.25 \mathrm{ml} / \mathrm{kg}$ (B.W) of $\mathrm{CCl}_{4}$ solution. The olive oil group received an equal volume of olive oil intraperitoneally. At $24 \mathrm{hr}$ post-injection, the rats were anesthetized with ether and blood was collected from the jugular vein. The liver was surgically removed and a random sample from each lobe was fixed in 10\% formalin, and then embedded in paraffin for hematoxylin-eosin (HE) staining and immunohistochemical staining. The remaining samples were kept frozen at $-80^{\circ} \mathrm{C}$ until the biochemical and gene expression analyses.

\section{Liver function tests along with fucoxanthin and fucoxanthinol levels}

Alanine aminotransferase (ALT) and aspartate aminotransferase (AST) levels in sera were measured using commercially available kits. The fucoxanthin and fucox- anthinol levels in sera were analyzed in two rats of the $\mathrm{CCl}_{4}+$ fucoxanthin group and two rats of the olive oil group using a modified method reported previously (Asai et al., 2008; Hashimoto et al., 2009). In brief, $500 \mu 1$ of serum was mixed with $1.0 \mathrm{ml}$ methanol and $2.0 \mathrm{ml}$ dichloromethane, and the lower dichloromethane layer was collected. The serum was added $2.0 \mathrm{ml}$ dichloromethane, then the lower layer was collected again. Both collected samples were used for assay. After evaporation, the residue from the dichloromethane layers was dissolved in $200 \mu \mathrm{l}$ ethanol. The amounts of fucoxanthin and fucoxanthinol in the ethanol solution were measured by liquid chromatography/ mass/ mass spectroscopy (LC/MS/MS) using a HPLC system (1100 series, Agilent Technologies, Santa Clara, CA, USA) and a QTrap mass spectrometer (API-4000, Applied Biosystems, Foster City, CA, USA). HPLC was performed on a TSKgel ODS-100V column $(150 \times 2.0 \mathrm{~mm}$ i.d., $3 \mu \mathrm{m}$, TOSOH Co. Ltd, Tokyo, Japan) at $30^{\circ} \mathrm{C}$ with acetonitrile/water $(8: 2)$ at a flow rate of $0.4 \mathrm{ml} / \mathrm{min}$. The injection volume was $10 \mu \mathrm{l}$. MS/MS detection was carried out with an atmospheric pressure chemical ionization (APCI) source. The APCI source was set in negative ionization mode. Quantitation was performed using multiple reaction monitoring mode of the transitions of $\mathrm{m} / \mathrm{z} 658 \rightarrow 598$ for fucoxanthin and $\mathrm{m} / \mathrm{z} 616$ $\rightarrow 558$ for fucoxanthinol, respectively.

\section{Liver pathology and immunohistochemistry}

After deparaffinization, liver samples were cut into 4- $\mu \mathrm{m}$ sections and stained with hematoxylin-eosin. Two independent observers evaluated 5 optical fields $(\times 200$ magnification) in each section chosen randomly under light microscopy, and counted the number of Councilman bodies per field. Then the mean number of Councilman bodies per section was calculated.

For immunohistochemistry, the sections were pretreated for 20 min with 3\% hydrogen peroxide in PBS to quench any endogenous peroxidase activity. Then the sections were subjected to immunohistochemical staining using antibodies against HO-1or Hsp 25, as mentioned above.

Areas of positive staining were quantified with ImageJ 1.38 x software (Wayne Rasbans, NIH, Bethesda, USA). The ratios of the positively stained areas were calculated from the ratio of the positive staining (brown color by immunohistochemistry) to the whole area of the liver captured in digital images. Three ocular fields $(\times 400$ magnification) per section were selected randomly from all of the samples, and the mean percentage of HO-1 positive cells per section was calculated. For the analysis of Hsp 25 positive cells, three ocular fields ( $\times 200$ magnifi- 
cation) per section were selected randomly, and the mean percentage of Hsp 25-positive cells was calculated.

\section{TUNEL staining}

Apoptotic bodies in the liver were detected by terminal deoxynucleotidyl - transferase (TdT)-mediated deoxyuridine triphosphate-digoxigenin (dUTP) nick-end labeling (TUNEL), which was performed using an In situ apoptosis detection kit (Roche Diagnostics). For analysis of the TUNEL- positive ratio, two independent observers evaluated 5 optical fields ( $\times 400$ magnification) for each specimen chosen randomly under light microscopy. Then the mean number of TUNEL-positive cells per specimen was calculated.

\section{Metallothionein 1/2 values in liver tissues}

Metallothionein (MT)1/2 values in liver tissues were assayed using the competitive ELISA according to the method described previously (Nakajima et al., 2010). Briefly, $50 \mu \mathrm{l}$ of sample specimen and $50 \mu \mathrm{l}$ of MT antibody were added per well and incubated for $1 \mathrm{hr}$ at $4^{\circ} \mathrm{C}$ in a microplate coated with rabbit MT2A. After incubation, wells were washed 3 times with PBS-T. Then, $100 \mu \mathrm{l}$ of HRP conjugated anti-rabbit IgG goat antibody was added per well and incubated for $1 \mathrm{hr}$ at room temperature. After incubation, wells were washed with PBS-T, and $100 \mu \mathrm{l}$ of color substrate 3,3',5,5' -tetramethylbenzine were added and reacted for $10 \mathrm{~min}$ at room temperature. After the reaction, $50 \mu \mathrm{l}$ of $1 \mathrm{~N} \mathrm{H}_{2} \mathrm{SO}_{4}$ was added to stop the reaction. Optical density was read at a $450 \mathrm{~nm}$ wave-length by a plate reader (MPRA4, Toso, Tokyo, Japan)

\section{Western blot analysis}

Liver tissues were homogenized in $3 \mathrm{X}$ volume of RIPA lysis buffer and centrifuged at $10,000 \times \mathrm{g}$ for $15 \mathrm{~min}$ at $4{ }^{\circ} \mathrm{C}$, and the supernatant was recovered for the Western blotting of HO-1 and $\beta$-actin. Proteins were separated using $12.5 \%$ SDS PAGE and transferred to PVDF membranes. Then the blotted membranes were blocked in Amersham ECL Prime Blocking Agent at $2 \%$ in T-PBS overnight at $4{ }^{\circ} \mathrm{C}$. After washing 3 times with PBS-T, the membranes were incubated for $1 \mathrm{hr}$ at room temperature with an anti-HO- 1 rabbit antibody $(1: 10,000)$ or anti- $\beta$ actin mouse antibody $(1: 10,000)$. Subsequently, the membrane was washed with PBS-T and was stained for $1 \mathrm{hr}$ at room temperature using peroxidase labeled anti-rabbit $\operatorname{IgG}(1: 150,000)$ or anti-mouse $\operatorname{IgG}(1: 75,000)$. After washing with PBS-T, the bound antibodies were visualized with the ECL-Prime Western Blotting Detection Reagent according to the manufacturer's protocol (GE Healthcare, Buckinghamshire, UK). Densitometry was used to measure the relative optical density of each specific band obtained after Western blotting.

\section{Real time polymerase chain reaction (real time-PCR)}

Quantitative real time-PCR was conducted in $10 \mu \mathrm{l}$ reactions containing LightCycler 480 SYBR Green I Master (Roshe Applied Science, Indianapolis, IN, USA) using the LightCycler 480 (Roshe Applied Science, Indianapolis, IN, USA).

The oligonucleotide primers for HO-1, hypoxia inducible factor(HIF)- $1 \alpha$ and GAPDH were as follows:

HO-1 Forward, 5' - CTGTGTAACCTCTGCTGTTCC -3'

HO-1 Reverse, 5'- CCACACTACCTGAGTCTACC -3'

HIF- $1 \alpha$ Forward, 5'-TGCTCATCAGTTGCCACTT-3'

HIF- $1 \alpha$ Reverse, 5'-TGGGCCATTCTGTGTGTA-3'

GAPDH Forward 5' - ATGGTGAAGGTCGGTGTGAAC

GAPDH Reverse 5'-TGTAGTTGAGGTCAATGAAGG-3'

Reaction mixtures were incubated for an initial denaturation at $95^{\circ} \mathrm{C}$ for $10 \mathrm{sec}$, followed by 40 PCR cycles. Each cycle consisted of $95^{\circ} \mathrm{C}$ for $10 \mathrm{sec}$ and $60^{\circ} \mathrm{C}$ for $10 \mathrm{sec}$, and $72^{\circ} \mathrm{C}$ for $10 \mathrm{sec}$, then $72^{\circ} \mathrm{C}$ for $10 \mathrm{~min}$. The expression level of each mRNA was normalized by comparison with that of GAPDH. And samples were quantified using standard cDNA dilutions.

\section{Statistical analysis}

Data were analyzed with Dr SPSS II (SPSS, Chicago, IL, USA). The statistical significance of difference was determined with the Tukey-Kramer test and Games-Howell test after 1-way ANOVA. Probabilities of $\mathrm{p}<0.05$ were regarded as statistically significant.

\section{RESULTS}

\section{MTT assay}

Proliferation of TRL1215 cells was inhibited by $\mathrm{CCl}_{4}$ in a dose- dependent manner (Fig. 1). Pretreatment with more than $10 \mu \mathrm{M}$ fucoxanthin attenuated the growth inhibition of TRL1215 cells by $\mathrm{CCl}_{4}$, while 0.5 and $1.0 \mu \mathrm{M}$ of fucoxanthin did not ameliorate $\mathrm{CCl}_{4}$-hepatotoxicity. In the case of hepatotoxicity induced by 2 or $5 \mathrm{mM}$ of $\mathrm{CCl}_{4}$, a high concentration of fucoxanthin $(25 \mu \mathrm{M})$ markedly reduced the hepatotoxicity compared to $10 \mu \mathrm{M}$ of fucoxanthin.

\section{Immunohistochemistry in Hc cells and TRL1215 cells}

HO-1 was clearly stained within the cytoplasm of Hc cells, and HO-1 expression was increased $24 \mathrm{hr}$ after the administration of $5 \mu \mathrm{M}$ fucoxanthin. In TRL1215 cell, the immunoreactivity of the HO-1 antibody was weak, and 
Anti-apoptotic effect of fucoxanthin on $\mathrm{CCl}_{4}$ toxicity

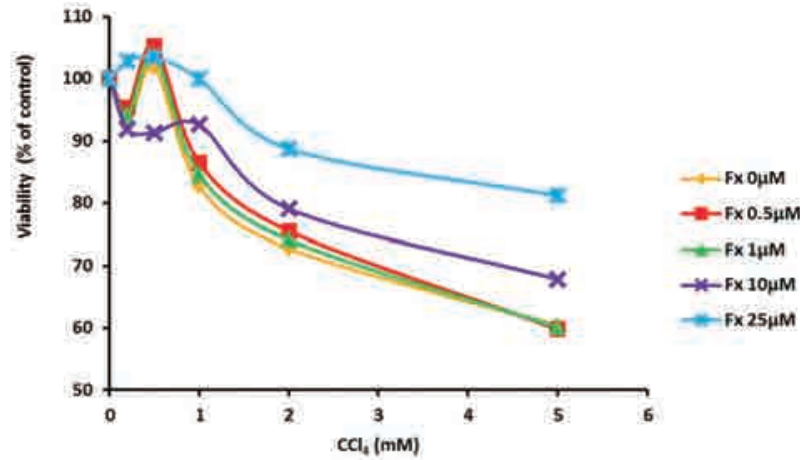

Fig. 1. Effect of fucoxanthin on $\mathrm{CCl}_{4}$-induced hepatocyte toxicity (MTT assay). The proliferation of TRL1215 cells was inhibited by $\mathrm{CCl}_{4}$ in a dose-dependent manner. Pretreatment with more than $10 \mu \mathrm{M}$ of fucoxanthin attenuated the growth inhibition of TRL1215 cells by $\mathrm{CCl}_{4}$. At $5 \mathrm{mM}$ of $\mathrm{CCl}_{4}$-hepatotoxicity, $25 \mu \mathrm{M}$ of fucoxanthin markedly reduced $\mathrm{CCl}_{4}$-hepatotoxicity compared to $10 \mu \mathrm{M}$ of fucoxanthin.

the intensity of the HO-1 stain was slightly increased by the administration of $5 \mu \mathrm{M}$ fucoxanthin (Fig. 2).

\section{Liver function tests, and the fuxoanthin and fucoxanthinol levels in rats}

The serum ALT levels (UI/l) in rats were significantly $(\mathrm{p}<0.05)$ elevated in the $\mathrm{CCl}_{4}+$ fucoxanthin group $(211.8$ $\pm 67.4)$ and the $\mathrm{CCl}_{4}$ group $(247.8 \pm 47.6)$ compared to the olive oil group $(40.0 \pm 7.0)$. The serum AST levels (UI/1) were also significantly elevated in the $\mathrm{CCl}_{4}+$ fucoxanthin group $(444.0 \pm 110.2)$ and the $\mathrm{CCl}_{4}$ group (482.6 \pm $21.7)$ compared to the olive oil group $(91.3 \pm 3.5)$. The $\mathrm{CCl}_{4}+$ fucoxanthin group displayed lower ALT and AST levels than the $\mathrm{CCl}_{4}$ group, although the difference was not significant. Fucoxanthin alone did not alter the ALT $(37.3 \pm 4.2)$ or AST levels $(151.0 \pm 61.4)$.

Fucoxanthin and its metabolite fucoxanthinol were detected in the sera of rats $28 \mathrm{hr}$ after the oral administration of $10 \mathrm{mg}$ fucoxanthin. The fucoxanthin levels $(0.322$ and $0.330 \mu \mathrm{g} / \mathrm{ml})$ were higher than the fucoxanthinol levels $(0.112$ and $0.180 \mu \mathrm{g} / \mathrm{ml})$. Neither fucoxanthin nor fucoxanthinol was detected in the sera of the olive oiltreated rats.

\section{Liver pathology}

$\mathrm{CCl}_{4}$-injected rat livers exhibited degenerative and/or necrotic hepatocytes concomitant with inflammatory cell infiltration and steatosis in the pericentral area. Hydrophic degeneration of the hepatocytes was observed around the apoptotic and/or necrotic hepatocytes. The lesions were similar in the $\mathrm{CCl}_{4}$ and $\mathrm{CCl}_{4}+$ fucoxantin groups. Council-
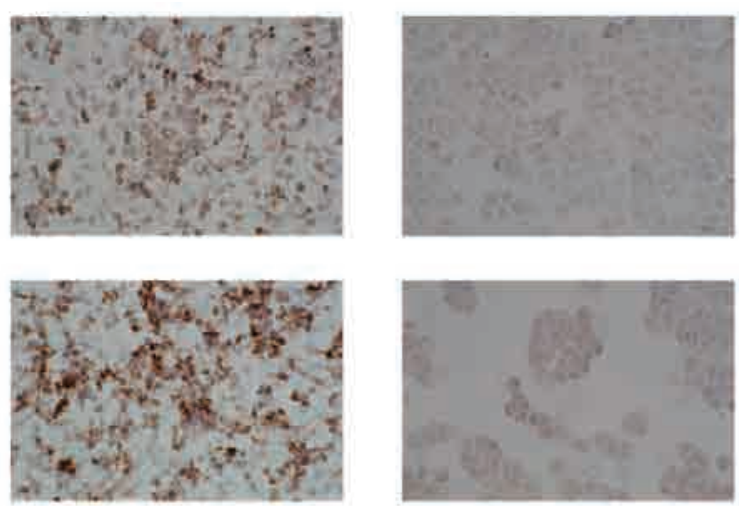

\begin{tabular}{l|l}
$\mathbf{a}$ & $\mathbf{b}$ \\
\hline $\mathbf{c}$ & $\mathbf{d}$
\end{tabular}

Fig. 2. Immunohistochemistry of HO-1 in liver cell cultures ( $\times 200)$. Reactivity for the HO-1 antibody was evident in Hc cells and weak in TRL1215 cells. HO-1 expression was mildly increased by $5 \mu \mathrm{M}$ of fucoxanthin. a, Hc cells $+0 \mu \mathrm{M}$ of fucoxanthin. b, TRL1215 cells + $0 \mu \mathrm{M}$ of fucoxanthin. c, Hc cells $+5 \mu \mathrm{M}$ of fucoxanthin. d, TRL1215 cells $+5 \mu \mathrm{M}$ of fucoxanthin.

man bodies, regarded as a sign of the apoptotic process (Kerr et al., 1979; Kanzler and Gall, 2000), appeared sporadically around the central vein in the $\mathrm{CCl}_{4}$-injected liver (Fig. 3 top left). The number of Councilman bodies was significantly $(\mathrm{p}<0.05)$ reduced in the $\mathrm{CCl}_{4}+$ fucoxanthin group compared with the $\mathrm{CCl}_{4}$ group . No histological changes were found in the liver of the fucoxanthin group or the olive oil group (Fig. 3 top right).

\section{TUNEL staining}

The TUNEL-positive nuclei of hepatocytes regarded as apoptotic cells were markedly increased in the pericentral area of the $\mathrm{CCl}_{4}$ group, whereas TUNEL-positive cells were scarcely seen in the $\mathrm{CCl}_{4}+$ fucoxanthin, fucoxanthin or olive oil group, respectively. The areas of the TUNEL- positive hepatocytes corresponded to the areas where Councilman bodies and/or degenerative hepatocytes were observed (Fig. 3 bottom left). The number of the TUNEL-positive hepatocyte nuclei in the $\mathrm{CCl}_{4}$ group was significantly $(\mathrm{p}<0.01)$ higher than in the $\mathrm{CCl}_{4}+$ fucoxantin group. However, there was no difference in the number of TUNEL-positive cells among the $\mathrm{CCl}_{4}+$ fucoxantin, fucoxanthin and olive oil groups (Fig. 3 bottom right).

\section{Immunohistochemistry of HO-1 in rat liver}

HO-1 was stained mainly in Kupffer cells and sporadically in the nuclei of hepatocytes, and the number and 
intensity of the HO-1-positive cells were increased after $\mathrm{CCl}_{4}$ injection. In the $\mathrm{CCl}_{4}+$ fucoxanthin group, numerous Kupffer cells strongly reacted to HO-1, but HO-1-positive cells were rarely observed in the fucoxanthin group or the olive oil group (Fig. 4 top left). The percentage of HO-1positive cells was significantly higher in the $\mathrm{CCl}_{4}+$ fucoxanthin group than the $\mathrm{CCl}_{4}$ group $(\mathrm{p}<0.05)$, the fucoxanthin group $(\mathrm{p}<0.01)$ and the olive oil group $(\mathrm{p}<0.05)$. There was no significant difference in the percentage of $\mathrm{HO}-1$-positive cells among the $\mathrm{CCl}_{4}$, fucoxanthin and olive oil groups (Fig. 4 top right).

\section{Western blotting of HO-1 in rat liver}

The HO- 1 protein was significantly $(\mathrm{p}<0.05)$ increased in the $\mathrm{CCl}_{4}+$ fucoxanthin group compared to the $\mathrm{CCl}_{4}$ group, was similar between the $\mathrm{CCl}_{4}$ group and the control (Fig. 4 bottom).

\section{Immunohistochemistry of Hsp25 in rat liver}

The Hsp25 protein was stained in both the cytoplasm and nuclei of the hepatocytes in the pericentral area of the $\mathrm{CCl}_{4}$ injected liver, an effect which was evidently reduced in rats with pretreatment of fucoxanthin compared to those without fucoxanthin. There was no staining of Hsp25 in hepatocytes of the fucoxanthin group or the olive oil group (Fig. 5 left). The percentage of Hsp25-positive cells was significantly $(\mathrm{p}<0.05)$ higher in the $\mathrm{CCl}_{4}$ group than the $\mathrm{CCl}_{4}+$ fucoxanthin group (Fig. 5 right).

\section{MT values in liver tissues}

MT1/2 values in liver tissues were unchanged by $\mathrm{CCL}_{4}$ injection, and. administration of fucoxanthin did not alter MT1/2 values in rat liver [MT1/2 values $(\mu \mathrm{g} / \mathrm{g})$ : the $\mathrm{CCl}_{4}+$ fucoxanthin group $27.1 \pm 8.9$, the $\mathrm{CCl}_{4}$ group $25.7 \pm 7.8$, the fucoxanthin group $22.4 \pm 3.1$, the olive oil group 35.4 $\pm 10.1]$.

\section{Real time RT-PCR}

HO-1 mRNA was slightly increased $24 \mathrm{hr}$ after $\mathrm{CCl}_{4}$ injection. HO-1 mRNA expression was higher in the $\mathrm{CCl}_{4}+$ fucoxanthin group than the $\mathrm{CCl}_{4}$ group, although the difference was not significant. Hypoxia inducible factor (HIF)-1 $\alpha$ mRNA expression was unchanged by $\mathrm{CCl}_{4}$ with/or without fucoxanthin (Fig. 6).

\section{DISCUSSION}

Since $\mathrm{CCl}_{4}$-induced liver injury is a commonly used model for the screening of the antihepatotoxic/hepatoprotective activities of drugs (Goldring et al., 2004; Lee and Johnson, 2004; Wen et al., 2006; Randle et al.,
2008), we examined the effect of fucoxanthin on $\mathrm{CCl}_{4}-$ indeuced hepatotoxicity. In the present study, MTT assay clearly demonstrated that fucoxanthin attenuated $\mathrm{CCl}_{4}$ induced hepatotoxicity. This effect was dose-dependent; $25 \mu \mathrm{M}$ of fucoxanthin was more effective than 10 $\mu \mathrm{M}$ for the hepatotoxicity induced by 2 or $5 \mathrm{mM}$ of $\mathrm{CCl}_{4}$. On the other hand, low concentrations, such as 0.5 and $1.0 \mu \mathrm{M}$ of fucoxanthin, did not attenuate $\mathrm{CCl}_{4}$-hepatotoxicity. In $\mathrm{CCl}_{4}$-injected rats, Councilman bodies, known as sign of the apoptotic process (Kerr et al., 1979; Kanzler and Gall, 2000), and apoptotic hepatocytes positive for TUNEL staining, were markedly evident in the centrilobular zone 3 area of the liver. No councilman bodies and few hepatocytes undergoing apoptosis were found in the liver specimens of the fucoxanthin and olive oil groups. This result confirmed the findings of previous studies (Irie et al., 2010; Srilaxmi et al., 2010), in which apoptotic hepatocytes were seen in zone 3 after the injection of a single dose of $\mathrm{CCl}_{4}$. The present study clearly showed that pretreatment of $\mathrm{CCl}_{4}$-injected rats with fucoxanthin significantly $(p<0.05)$ reduced the presence of Councilman bodies and hepatocyte apoptosis. Hepatocyte apoptosis in the $\mathrm{CCl}_{4}+$ fucoxanthin group was attenuated to an extent close to the olive oil group. In other words, $\mathrm{CCl}_{4^{-}}$ induced hepatocyte apoptosis was apparently prevented by pretreatment with fucoxanthin, suggesting that fucoxanthin has an anti-apoptotic effect and inhibited the toxic damage. There have been a number of reports on the anticancer properties of fucoxanthin through apoptosis induction (Hosokawa et al., 2004; Kotake-Nara et al., 2005; Yu et al., 2011), while the anti-apoptotic effect of fucoxanthin was reported in only a single in vitro study (Heo and Jeon, 2009). This is the first study to demonstrate the antiapoptotic effect of fucoxanthin in vivo.

The anti-apoptotic mechanism of the effect of fucoxanthin on $\mathrm{CCl}_{4}$-induced acute hepatotoxicity remains to be elucidated; however, HO-1 induction by fucoxanthin has attracted interest in terms of protection against $\mathrm{CCl}_{4}$-induced hepatotoxicity. The HO- 1 induced by $\mathrm{CCl}_{4}$ degrades heme to carbon monoxide, which possesses anti-inflammatory, anti-proliferative and anti-apoptotic activities (Farombi and Surh, 2006). Indeed, overexpression of $\mathrm{HO}-1$ with glycyrrhizin alleviates $\mathrm{CCl}_{4}$-induced acute liver injury in mice (Lee et al., 2007). The present in vitro study revealed that $5 \mu \mathrm{M}$ of fucoxanthin increased HO-1 expression in both Hc cells and TRL1215 cells. In the rat liver $24 \mathrm{hr}$ after $\mathrm{CCl}_{4}$ injection, $\mathrm{HO}-1$ was markedly expressed, principally in Kupffer cells and sporadically in the nuclei of hepatocytes. The ratio of HO-1-positive cells significantly $(\mathrm{p}<0.05)$ higher in rats treated with $\mathrm{CCl}_{4}$ and fucoxanthin than with $\mathrm{CCl}_{4}$ alone. In addition, 

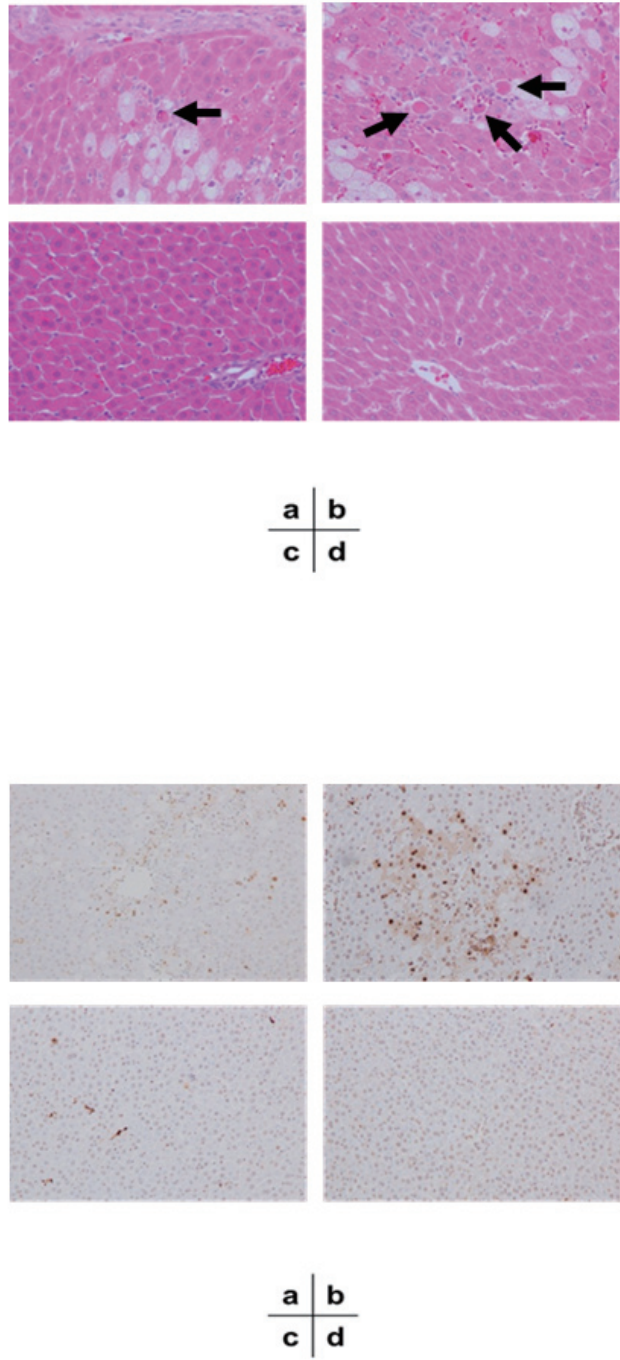
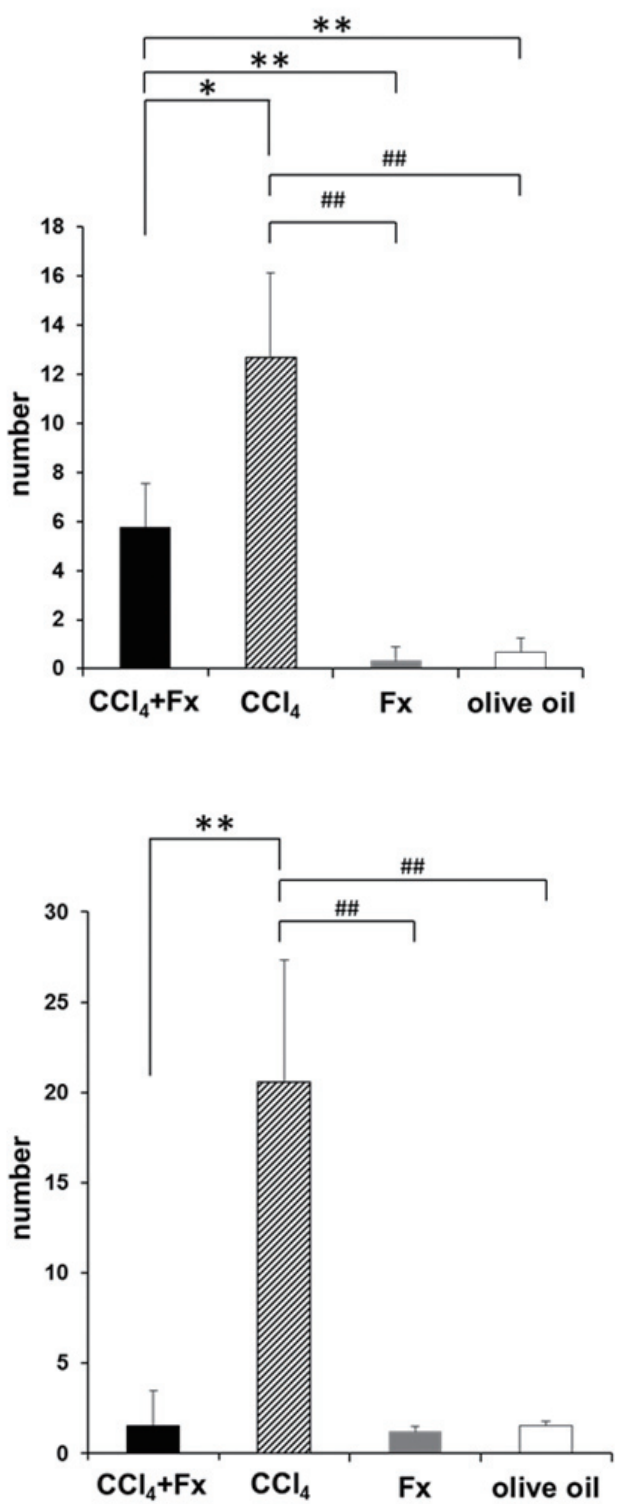

Fig. 3. HE staining $(\times 400)$ and TUNEL staining $(\times 200)$ of rat liver. Top: a representative photomicrograph of the liver histology stained with $\mathrm{HE}$ in each group (a. $\mathrm{CCl}_{4}+$ fucoxanthin group, b. $\mathrm{CCl}_{4}$ group, c. fucoxanthin group, d. olive oil group). Necrosis and steatosis of the hepatocytes and inflammatory cell infiltration are seen in the pericentral area of the lobule in the $\mathrm{CCl}_{4}$-injected rat. Hydrophic degeneration of hepatocytes is scattered around the area of hepatocyte necrosis. Councilman bodies appear sporadically around the central vein in the $\mathrm{CCl}_{4}$-injected liver. No changes are evident in the liver of the fucoxanthin group or olive oil group. The arrow indicates the Councilman bodies (left). The number of Councilman bodies was significantly decreased in the $\mathrm{CCl}_{4}+$ fucoxanthin group compared to the $\mathrm{CCl}_{4}$ group (right). Each value (mean \pm S.D., $\mathrm{n}=3-5$ ) is the number of Councilman bodies per section. Bottom: a representative photomicrographs of TUNEL staining in each group. TUNEL is stained in the nuclei of hepatocytes and is markedly increased in the pericentral area of the $\mathrm{CCl}_{4}$ group. TUNEL positive cells are only rarely evident in the $\mathrm{CCl}_{4}+$ fucoxanthin group, the fucoxanthin group and the olive oil group (left). The number of TUNEL-positive cells is significantly higher in the $\mathrm{CCl}_{4}$ group than in the $\mathrm{CCl}_{4}+$ fucoxantin group (right). Each value (mean \pm S.D., $\mathrm{n}=3-5$ ) is the percent of TUNEL-positive cells per section. $\mathrm{CCl}_{4}$ : the $\mathrm{CCl}_{4}$ group, $\mathrm{CCl}_{4}+\mathrm{Fx}$ : the $\mathrm{CCl}_{4}+$ fucoxanthin group, $\mathrm{Fx}$ : the fucoxanthin group, olive oil: the olive oil group. ${ }^{*} \mathrm{p}<0.05$ compared with the $\mathrm{CCl}_{4}$ +fucoxanthin group. ${ }^{* *} \mathrm{p}<0.01$ compared with the $\mathrm{CCl}_{4}$ +fucoxanthin group. $\# \mathrm{p}<0.01$ compared with the $\mathrm{CCl}_{4}$ group. 

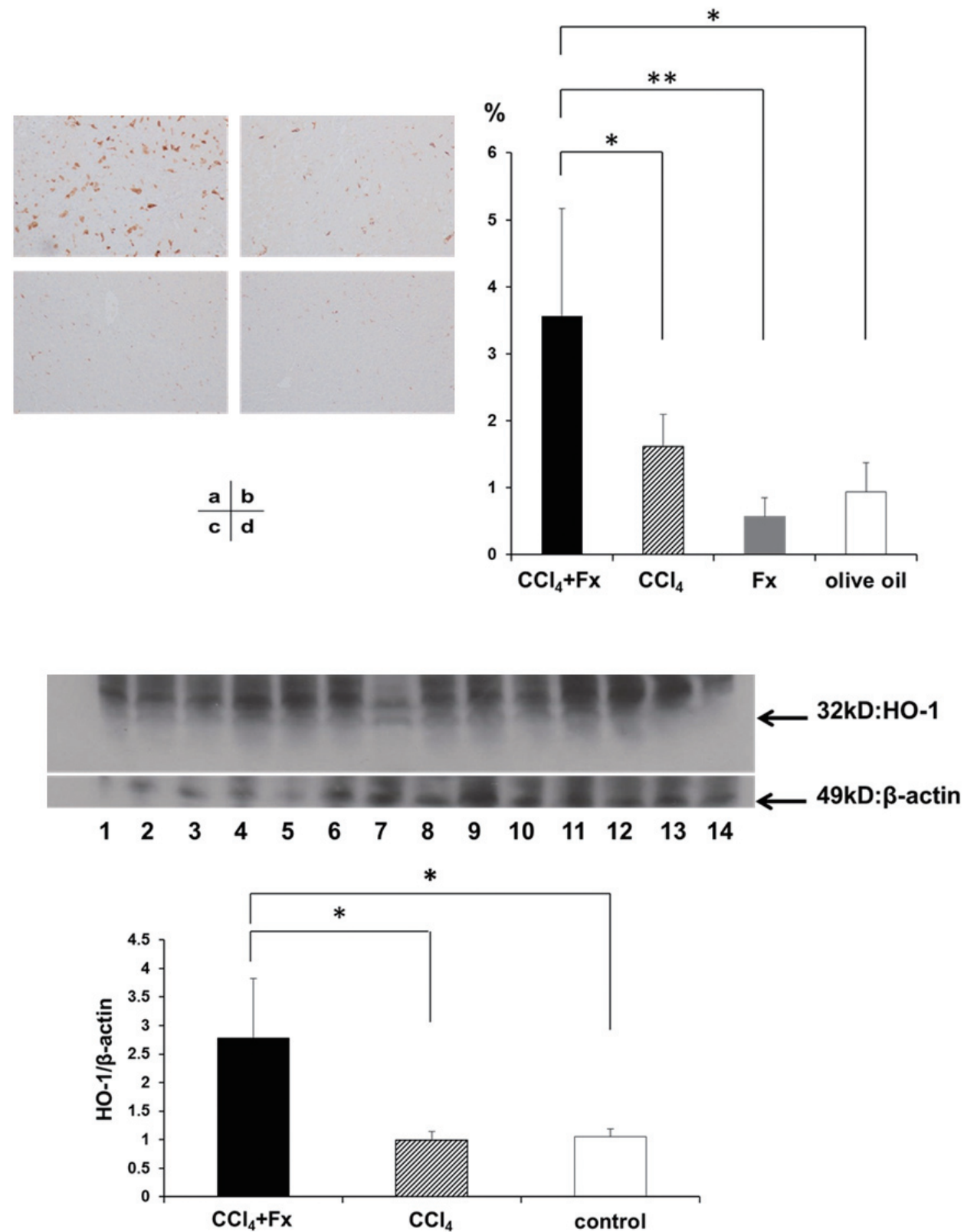

Fig. 4. HO-1 protein in rat liver. Top: a representative immunohistochemical staining of HO-1 in rat liver $(\times 200)$ in each group (a. the $\mathrm{CCl}_{4}+$ fucoxanthin group, b. the $\mathrm{CCl}_{4}$ group, c. the fucoxanthin group and d. the olive oil group). HO- 1 is stained markedly in Kupffer cells and sporadically in the nuclei of hepatocytes in the $\mathrm{CCl}_{4}+$ fucoxanthin group. HO-1-positive cells are rarely observed in the $\mathrm{CCl}_{4}$, fucoxanthin and olive oil groups (left). The percentage of $\mathrm{HO}-1$-positive cells in the $\mathrm{CCl}_{4}+$ fucoxanthin group was significantly increased compared to those of the other three groups (right). Each value (mean \pm

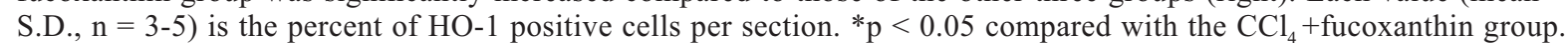
$* * \mathrm{p}<0.01$ compared with the $\mathrm{CCl}_{4}+$ fucoxanthin group. Bottom: Western blotting of HO-1 in rat liver. Equal loading was assessed with an anti- $\beta$-actin antibody. The $32 \mathrm{kDa} \mathrm{HO}-1$ band and $49 \mathrm{kDa} \beta$-actin band are indicated by arrows. Lane 1-5 the $\mathrm{CCl}_{4}+$ fucoxanthin group. Lane 6-10 the $\mathrm{CCl}_{4}$ group. Lane 11,12 the fucoxanthin group. Lane 13,14 the olive oil group. Western blots were scanned by densitometry and the data is presented as relative intensity units.. Each bar represents the mean \pm S.D. of four to five rats. The control consists of two fucoxanthin groups and two olive oil groups. $* \mathrm{P}<0.05$ compared with the $\mathrm{CCl}_{4}+$ fucoxanthin group. 

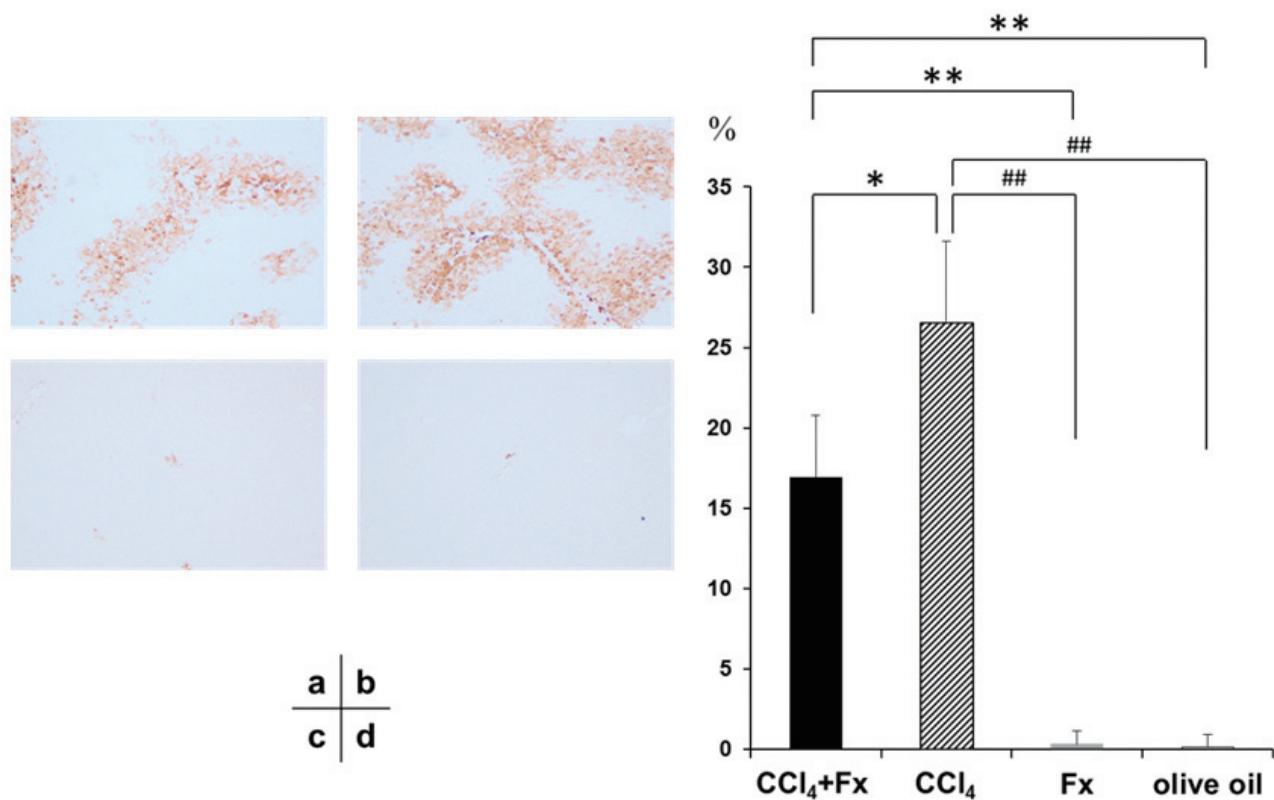

Fig. 5. Immunohistochemistry of Hsp25 in rat liver. A representative photomicrograph of Hsp25 staining $(\times 200)$ in each group (a. the $\mathrm{CCl}_{4}+$ fucoxanthin group, b. the $\mathrm{CCl}_{4}$ group, c. the fucoxanthin group and d. the olive oil group) is shown in Fig. 5 left. The Hsp25 protein is stained in the cytoplasm and nuclei of hepatocytes in the pericentral area of the $\mathrm{CCl}_{4}$ injected liver, which effect is significantly reduced in the rats receiving the pretreatment with fucoxanthin. Hsp25 is not stained in the hepatocytes of the fucoxanthin group or olive oil group. The percentage of Hsp25-positive cells in the $\mathrm{CCl}_{4}+$ fucoxanthin group is significantly decreased compared to the $\mathrm{CCl}_{4}$ group (Fig. 5 right). Each value (mean \pm S.D., $\mathrm{n}=3-5$ ) is the percent of Hsp 25-positive cells per section. ${ }^{*} \mathrm{p}<0.05$ compared with the $\mathrm{CCl}_{4}+$ fucoxanthin group. ${ }^{*} \mathrm{p}<0.01$ compared with the $\mathrm{CCl}_{4}+$ fucoxanthin group. \#\# $\mathrm{p}<0.01$ compared with the $\mathrm{CCl}_{4}$ group.

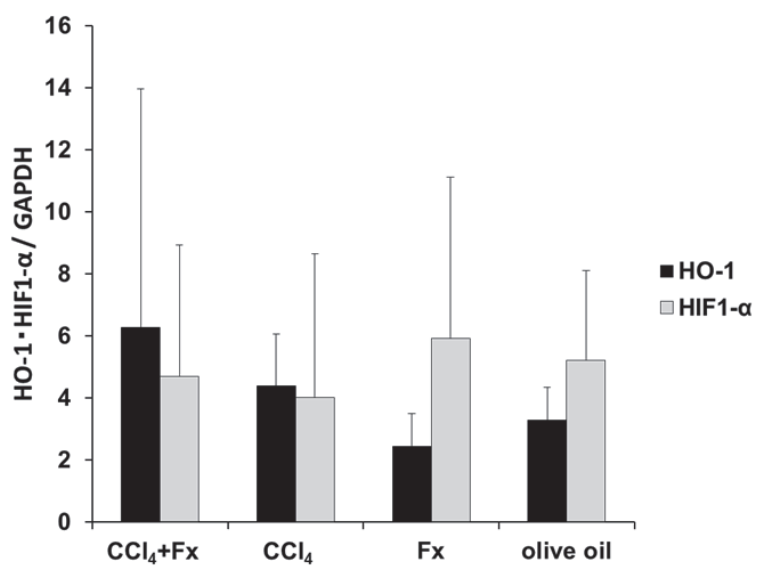

Fig. 6. HO-1 and HIF-1 $\alpha$ mRNA expression in rat liver. HO-1 mRNA expression in the liver was measured by real time PCR analysis, and samples were quantified using standard cDNA dilutions. HO-1 mRNA expression is higher in the $\mathrm{CCl}_{4}+$ fucoxanthin group than the $\mathrm{CCl}_{4}$ group, the fucoxanthin group and the olive oil group, although the difference is not significant. HIF-1 $\alpha$ mRNA expression was unchanged by $\mathrm{CCl}_{4}$ with/or without fucoxanthin. The results are presented as the mean \pm S.D. pretreatment with fucoxanthin significantly $(\mathrm{p}<0.05)$ increased the hepatic $\mathrm{HO}-1$ protein content in $\mathrm{CCl}_{4}$-injected rats. HO-1 mRNA expression was up-regulated in the following order, the $\mathrm{CCl}_{4}+$ fucoxanthin group, the $\mathrm{CCl}_{4}$ group, the olive oil group and the fucoxanthin group, although the difference between the groups was not significant. This result is similar to one reported by Liu et al. (2011), in which fucoxanthin significantly increased HO-1 protein expression, but mildly up-regulated HO-1 mRNA in murine hepatic BNL CL.2 cells after incubation for $24 \mathrm{hr}$. Sass et al. (2003) showed that up-regulation of endogenous HO-1 rescued mice from the apoptotic liver damage induced by anti-CD3 Ab, lipopolysaccharide or tumor necrosis factor- $\alpha$. When these data are taken into consideration together with our in vivo and in vitro findings, it is suggested that fucoxanthin exerts an anti-apoptotic effect on $\mathrm{CCl}_{4}$-induced apoptotic hepatocytes via HO-1 induction.

The Keap1-Nrf2-ARE signaling pathway has emerged as an important regulator in the mammalian detoxication of $\mathrm{CCl}_{4}$ through the up-regulation of the cellular antioxidant enzyme HO-1 (Randle et al., 2008). HO-1 induction 
by fucoxanthin is mediated through several pathways. HO-1 induction by fucoxanthin was previously evaluated in detail using liver BNL CL.2 cells (Liu et al., 2011), with the result that fucoxanthin significantly increased the phosphorylation of ERK and p38 and markedly increased nuclear Nrf2 protein accumulation. Moreover, fucoxanthin was shown to significantly enhance the binding activities of nuclear Nrf2 with ARE, and to increase the mRNA and protein expression of HO-1. Furthermore, siRNA inhibition of Nrf2 led to markedly decreased HO-1 protein expression. However, there has been no reported study in vivo on HO-1 induction by fucoxanthin. An in vivo study is necessary to elucidate whether the oral administration of fucoxanthin is absorbed via the intestinal tract. Sugawara et al. (2002) showed that dietary fucoxanthin was deacetylated into fucoxanthinol in the intestinal tract and incorporated as fucoxanthinol into the blood circulation system. A similar metabolic pathway of fucoxanthin was also reported in rats (Sangeetha et al., 2010). The present study detected fucoxanthin and its metabolite of fucoxanthinol in the sera of rats collected $28 \mathrm{hr}$ after oral administration of fucoxanthin, indicating that fucoxanthin, at least partly, was able to be absorbed through the intestinal tract in rats. Since fucoxanthin enhances HO-1 induction in the rat liver, fucoxanthin may exert its antioxidant activity through an activation of the Nrf2/ARE system, as was reported in the cultured hepatocytes (Liu et al., 2011).

Hsp function as molecular chaperones in regulating cellular homeostasis and promoting cell survival (Ellis, 2007). Many studies have demonstrated that Hsp-induced cytoprotection can be attributed in part to the suppression of apoptosis (Concannon et al., 2001). Hsp25 is one of the major classes of Hsp families in the rat and mouse, a homolog for human Hsp27, and the inhibitory effect of Hsp25 on the apoptosis pathway is well known (Salminen et al., 1997; Sreedhar et al., 2004). More recently, the induction of the Hsp25 protein and apoptotic cells were reported in the pericentral area of rat liver after $\mathrm{CCl}_{4}$ injection (Fujisawa et al., 2012). In line with this report, the present study showed that apoptotic cells, demonstrable by the TUNEL method, were obviously seen in the pericentral area, corresponding to the area where Hsp25 was expressed. However, the marked induction of Hsp25 by $\mathrm{CCl}_{4}$ in rat liver was significantly $(\mathrm{p}<0.05)$ decreased by pretreatment with fucoxanthin, and fucoxanthin alone did not induce Hsp25 expression immunohistochemically. Thus, the anti-apoptotic effect of fucoxanthin is unlikely to be due to Hsp25 induction. Since fucoxanthin acts as an antioxidant under hypoxic conditions (Nomura et al., 1997), we have also investigated hypoxia inducible fac- tor (HIF)- $1 \alpha$ and metallothionein (MT) $1 / 2$ expression, critical hypoxia-induced proteins (Murphy et al., 2008; Adams et al., 2009), in the resent study. Consequently, it was also shown that HIF- $1 \alpha$ and MT1/2 did not participate in the anti-apoptotic effect of fucoxanthin on $\mathrm{CCl}_{4}$ hepatotoxicity .

Hepatocyte apoptosis sometimes precedes the onset of necrosis, or coexists with it, therefore a drug which affords protection against hepatocyte apoptosis also protects against the secondary necrosis of liver tissue (Herrera et al., 2001; Weber et al., 2003). In the present study, the serum AST and ALT levels were lower in the $\mathrm{CCl}_{4}+$ fucoxanthin group than the $\mathrm{CCl}_{4}$ group, but the difference was not significant, despite a marked suppression for hepatocytes apoptosis. The reason is speculated to be that fucoxanthin markedly suppresses apoptosis but mildly attenuates necrosis in hepatocytes subjected to $\mathrm{CCl}_{4}$ toxicity.

In conclusion, fucoxanthin, via the induction of $\mathrm{HO}-1$, decisively reduces hepatocyte apoptosis induced by $\mathrm{CCl}_{4}$. Clarification of the anti-apoptotic pathway mediated by fucoxanthin will require future study. There is increasing evidence that HO-1 is protective in several disparate models of hepatic stress. As the induction of HO-1 expression by fucoxanthin if of potential therapeutic value, further experiments using well designed in vivo models to properly evaluate the efficacy of fucoxanthin are warranted.

\section{ACKNOWLEDGMENTS}

This work was partially supported by Grants-in-Aid for Scientific Research from the Japan Society for the Promotion of Science. The authors thank Dr. Masahiko Iha (South Product Co.), Dr. Katsuyuki Nakajima (Otsuka Pharmaceutical Co., Ltd.) and Dr. Toshiharu Tokita (Graduate School of Health Sciences, Gunma University) for helpful suggestion and assistance. Pacific Edit reviewed the manuscript prior to submission.

\section{REFERENCES}

Abidov, M., Ramazanov, Z., Seifulla, R. and Grachev, S. (2010): The effects of xanthigen in the weight management of obese premenopausal women with non-alcoholic fatty liver disease and normal liver fat. Diabetes Obes. Metab., 12, 72-81.

Adams, J.M., Difazio, L.T., Rolandelli, R.H., Luján, J.J., Haskó, G., Csóka, B., Selmeczy, Z. and Németh, Z.H. (2009): HIF-1: a key mediator in hypoxia. Acta Physiol. Hung., 96, 19-28.

Asai, A., Yonekura, L. and Nagao, A. (2008): Low bioavailability of dietary epoxyxanthophylls in humans. Br. J. Nutr., 100, 273-277.

Concannon, C.G., Orrenius, S. and Samali, A. (2001): Hsp27 inhibits cytochrome c-mediated caspase activation by sequestering both pro-caspase-3 and cytochrome c. Gene Expr., 9, 195-201. 
Anti-apoptotic effect of fucoxanthin on $\mathrm{CCl}_{4}$ toxicity

Dembitsky, V.M. and Maoka, T. (2007): Allenic and cumulenic lipids. Prog. Lipid. Res., 46, 328-375.

D’Orazio, N., Gemello, E., Gammone, M.A., de Girolamo, M., Ficoneri, C. and Riccioni, G. (2012): Fucoxantin: a treasure from the sea. Mar. Drugs, 10, 604-616.

Ellis, R.J. (2007): Protein misassembly: macromolecular crowding and molecular chaperones. Adv. Exp. Med. Biol., 594, 1-13.

Farombi, E.O. and Surh, Y. J. (2006): Heme oxygenase-1 as a potential therapeutic target for hepatoprotection. J. Biochem. Mol. Biol., 39, 479-491.

Fujisawa, K., Yabuuchi, C., Izawa, T., Kuwamura, M., Takasu, N., Torii, M. and Yamate, J. (2012): Expression patterns of heat shock protein 25 in carbon tetrachloride-induced rat liver injury. Exp. Toxicol. Pathol. (in press).

Goldring, C.E., Kitteringham, N.R., Elsby, R., Randle, L.E., Clement, Y.N., Williams, D.P., McMahon, M., Hayes, J.D., Itoh, K., Yamamoto, M. and Park, B.K. (2004): Activation of hepatic Nrf2 in vivo by acetaminophen in CD-1 mice. Hepatology, 39, $1267-1276$

Hashimoto, T., Ozaki, Y., Taminato, M., Das, S.K., Mizuno, M., Yoshimura, K., Maoka, T. and Kanazawa, K. (2009): The distribution and accumulation of fucoxanthin and its metabolites after oral administration in mice. Br. J. Nutr., 102, 242-248.

Heo, S.J. and Jeon, Y.J. (2009): Protective effect of fucoxanthin isolated from Sargassum siliquastrum on UV-B induced cell damage. J. Photochem. Photobiol. B., 95, 101-107.

Herrera, B., Alvarez, A.M., Sánchez, A., Fernández, M., Roncero, C., Benito, M. and Fabregat, I. (2001): Reactive oxygen species (ROS) mediates the mitochondrial-dependent apoptosis induced by transforming growth factor (beta) in fetal hepatocytes. FASEB J., 15, 741-751.

Hosokawa, M., Kudo, M., Maeda, H., Kohno, H., Tanaka, T., and Miyashita, K. (2004): Fucoxanthin induces apoptosis and enhances the antiproliferative effect of the PPAR-gamma ligand, troglitazone, on colon cancer cells. Biochim. Biophys., 1675, 113-119.

Irie, H., Asano-Hoshino, A., Sekino, Y., Nogami, M., Kitagawa, T. and Kanda, H. (2010): Striking LD50 variation associated with fluctuations of CYP2E1-positive cells in hepatic lobule during chronic CCl4 exposure in mice. Virchows Arch., 456, 423-431.

Itoh, K., Wakabayashi, N., Katoh, Y., Ishii, T., Igarashi, K., Engel, J.D. and Yamamoto, M. (1999): Keap1 represses nuclear activation of antioxidant responsive elements by Nrf2 through binding to the amino-terminal Neh2 domain. Genes Dev., 13, 76-86.

Kanzler, S. and Gall, P. R. (2000): Apoptosis and the liver. Semin Cancer Biol., 10, 173-184.

Kerr, J.F., Cooksley, W.G., Searle, J., Halliday, J.W., Halliday, W.J., Holder, L., Roberts, I., Burnett, W. and Powell, L.W. (1979): The nature of piecemeal necrosis in chronic active hepatitis. Lancet, 2, 827-828.

Kim, K.N., Heo, S.J., Yoon, W.J., Kang, S.M., Ahn, G., Yi, T.H. and Jeon, Y.J. (2010): Fucoxanthin inhibits the inflammatory response by suppressing the activation of NF- $\mathrm{\kappa B}$ and MAPKs in lipopolysaccharide-induced RAW 264.7 macrophages. Eur. J. Pharmacol., 649, 369-375.

Kotake-Nara, E., Terasaki, M. and Nagao, A. (2005): Characterization of apoptosis induced by fucoxanthin in human promyelocytic leukemia cells. Biosci. Biotechnol. Biochem., 69, 224-227.

Lee, J.M. and Johnson, J.A. (2004): An important role of Nrf2-ARE pathway in the cellular defense mechanism. J. Biochem. Mol. Biol., 37, 139-143.

Lee, C.H., Park, S.W., Kim, Y.S., Kang, S.S., Kim, J.A., Lee, S.H. and Lee, S.M. (2007): Protective mechanism of glycyrrhizin on acute liver injury induced by carbon tetrachloride in mice. Biol. Pharm. Bull., 30, 1898-1904

Liu, C.L., Chiu, Y.T. and Hu, M.L. (2011): Fucoxanthin enhances HO-1 and NQO1 expression in murine hepatic BNL CL.2 cells through activation of the Nrf2/ARE system partially by its prooxidant activity. J. Agric. Food Chem., 59, 11344-11351.

Maeda, H., Hosokawa, M., Sashima, T., Funayama, K. and Miyashita, K. (2005): Fucoxanthin from edible seaweed, Undaria pinnatifida, shows antiobesity effect through UCP1 expression in white adipose tissues. Biochem. Biophys. Res. Commun., 332, 392-397.

Manibusan, M.K., Odin M. and Eastmond, D.A. (2007): Postulated carbon tetrachloride mode of action: A review. J. Environ. Sci. Health C Environ. Carcinog. Ecotoxicol. Rev., 25, 185-209.

Miyashita, K. (2009): Function of marine carotenoids. Forum Nutr., 61, 136-146.

Murphy, B.J., Kimura, T., Sato, B.G., Shi, Y. and Andrews, G.K. (2008): Metallothionein induction by hypoxia involves cooperative interactions between metal-responsive transcription factor-1 and hypoxia-inducible transcription factor-1alpha. Mol. Cancer Res., 6, 483-490.

Nakajima, K., Kodaira, T., Kato, M., Nakazato, K., Tokita, Y., Kikuchi, H., Sekine, H., Suzuki, K. and Nagamine, T. (2010): Development of an enzyme-linked immunosorbent assay for metallothionein-I and -II in plasma of humans and experimental animals. Clin. Chim. Acta, 411, 758-761.

Nagamine, T., Takada, H., Kusakabe, K., Nakazato, K., Sakai, T., Oikawa, M., Kamiya, T. and Arakawa, K. (2008): Intracellular changes of metal elements by fucoidan extracted from Brawn Seaweed (Cladosiphon okamuranus). Biol. Trace Elem. Res., 124, 60-69.

Nomura, T., Kikuchi, M., Kubodera, A. and Kawakami, Y. (1997): Proton-donative antioxidant activity of fucoxanthin with 1,1-diphenyl-2-picrylhydrazyl (DPPH). Biochem. Mol. Biol. Int., 42, 361-370.

Ohkawa, H., Ohishi, N. and Yagi, K. (1979): Assay for lipid peroxides in animal tissues by thiobarbituric acid reaction. Anal. Biochem., 95, 351-358.

Osawa, Y., Banno, Y., Nagaki, M., Brenner, D.A., Naiki, T., Nozawa, Y., Nakashima, S. and Moriwaki, H. (2001): TNF-alpha-induced sphingosine 1-phosphate inhibits apoptosis through a phosphatidylinositol 3-kinase/Akt pathway in human hepatocytes. J. Immunol., 167, 173-180.

Ozaki, M. and Masuda, Y. (1993): Carbon tetrachloride-induced cell death in perfused livers from phenobarbital-pretreated rats under hypoxic conditions and various ionic milieu. Further evidence for calcium-dependent irreversible changes. Biochem. Pharmacol., 46, 2039-2049.

Randle, L.E., Goldring, C.E., Benson, C.A., Metcalfe, P.N., Kitteringham, N.R., Park, B.K. and Williams, D.P. (2008): Investigation of the effect of a panel of model hepatotoxins on the Nrf2-Keap1 defence response pathway in CD-1 mice. Toxicology, 243, 249-260.

Sachindra, N.M., Sato, E., Maeda, H., Hosokawa, M., Niwano, Y., Kohno, M. and Miyashita, K. (2007): Radical scavenging and singlet oxygen quenching activity of marine carotenoid fucoxanthin and its metabolites. J. Agric. Food Chem., 55, 8516-8522.

Sakai, S., Sugawara, T., Matsubara, K. and Hirata, T. (2009): Inhibitory effect of carotenoids on the degranulation of mast cells via suppression of antigen-induced aggregation of high affinity IgE receptor. J. Biol. Chem., 284, 28172-28179. 


\section{Kaneko et al.}

Salminen,W.F.Jr., Voellmy, R. and Roberts, S.M. (1997): Differential heat shock protein induction by acetaminophen and a nonhepatotoxic regioisomer, 3'-hydroxyacetanilide, in mouse liver. J. Pharmacol. Exp. Ther., 282, 1533-1540.

Sangeetha, R.K., Bhaskar, N., Divakar, S. and Baskaran, V. (2010): Bioavailability and metabolism of fucoxanthin in rats: structural characterization of metabolites by LC-MS (APCI). Mol. Cell. Biochem., 333, 299-310.

Sass, G., Soares, M.C., Yamashita, K., Seyfried, S., Zimmermann, W.H., Eschenhagen, T., Kaczmarek, E., Ritter, T., Volk, H.D. and Tiegs, G. (2003): Heme oxygenase-1 and its reaction product, carbon monoxide, prevent inflammation-related apoptotic liver damage in mice. Hepatology, 38, 909-918.

Slater, T.F. (1966): Necrogenic action of carbon tetrachloride in the rat: a speculative mechanism based on activation. Nature, 209, 36-40.

Sreedhar, A.S. and Csermely, P. (2004): Heat shock proteins in the regulation of apoptosis: new strategies in tumor therapy: a comprehensive review. Pharmacol. Ther., 101, 227-257.

Srilaxmi, P., Sareddy, G.R., Kavi Kishor, P.B., Setty, O.H. and Babu, P.P. (2010): Protective efficacy of natansnin, a dibenzoyl glycoside from Salvinia natans against $\mathrm{CCl}_{4}$ induced oxidative stress and cellular degeneration in rat liver. BMC Pharmacol., 12, 1013.
Sugawara, T., Baskaran, V., Tsuzuki, W. and Nagao, A. (2002): Brown algae fucoxanthin is hydrolyzed to fucoxanthinol during absorption by Caco-2 human intestinal cells and mice. J. Nutr., 132, 946-951.

Thomas, R.S., Rank, D.R., Penn S.G., Zastrow, G.M., Hayes, K.R., Pande, K, Glover, E., Silander, T., Craven, M.W., Reddy, J.K., Jovanovich, S.B. and Bradfield, C.A. (2001): Identification of toxicologically predictive gene sets using cDNA microarrays. Mol. Pharmacol., 60, 1189-1194.

Weber, L.W., Boll, M. and Stampfl, A. (2003): Hepatotoxicity and mechanism of action of haloalkanes: Carbon tetrachloride as a toxicological model. Crit. Rev. Toxicol., 33, 105-136.

Wen, T., Guan, L., Zhang, Y.L. and Zhao, J.Y. (2006): Dynamic changes of heme oxygenase- 1 and carbon monoxide production in acute liver injury induced by carbon tetrachloride in rats. Toxicology, 228, 51-57.

Wong, F.W.Y., Chan, W.Y. and Lee, S.S.T. (1995): Resistance to carbon tetrachloride-induced hepatoxicity in mice which lack CYP2E1 expression. Toxicol. Appl. Pharmacol., 153, 109-118.

Yu, R.X., Hu, X.M., Xu, S.Q., Jiang, Z.J. and Yang, W. (2011): Effects of fucoxanthin on proliferation and apoptosis in human gastric adenocarcinoma MGC-803 cells via JAK/STAT signal pathway. Eur. J. Pharmacol., 657, 10-19. 